\section{Familial hypercholesterolemia: Clarifications}

To the Editor: The article by Shah and colleagues ${ }^{1}$ is an excellent review of familial hypercholesterolemia (FH) and highlights an underdiagnosed condition on which clinicians can make a significant impact. I would like to clarify two points:

First, as the authors describe, tendon xanthoma is mostly pathognomonic for FH. Xanthelasma, however, is nonspecific for this condition and does not appear in any of the diagnostic criteria.

Second, the American Diabetes Association (ADA) was one of the societies involved in the 2018 American Heart Association/American College of Cardiology multisociety guidelines, ${ }^{2}$ and the 2020 ADA Standards of Care still reflect a low-density lipoprotein cholesterol (LDL-C) threshold for intensification of $70 \mathrm{mg} / \mathrm{dL}$ in patients at very high risk. ${ }^{3}$ I believe the authors meant to refer to the 2017 American Association of Clinical Endocrinologists/American College of Endocrinology guidelines that introduced a new category of "extreme risk" with an LDL-C treatment goal of less than $55 \mathrm{mg} /$ $\mathrm{dL}$, which includes patients with heterozygous $\mathrm{FH}$ and established atherosclerotic cardiovascular disease. ${ }^{4}$ This treatment goal was mirrored by the 2019 European Society of Cardiology/European Atherosclerosis Society guidelines. $^{5}$

TAHER MODARRESSI, MD

Diabetes \& Endocrine Associates of Hunterdon Flemington, NJ 08822

-REFERENCES

1. Shah NP, Ahmed HM, Tang WH. Familial hypercholesterolemia: detect, treat, and ask about family. Cleve Clin J Med 2020; 87(2):109-120. doi:10.3949/ccjm.87a.19021

2. Grundy SM, Stone NJ, Bailey AL, et al. 2018 AHAVACC/AACVPR/AAPA/ABC ACPM/ADAVAGS/APhAVASPC/NLA/PCNA guideline on the management of blood cholesterol: a report of the American College of Cardiology/American Heart Association Task Force on Clinical Practice Guidelines. Circulation 2019; 139(25):e1082-e1143. doi: 10.1161/CIR.0000000000000625

3. American Diabetes Association. 10. Cardiovascular disease and risk management: standards of medical care in diabetes - 2020. Diabetes Care 2020; 43(suppl1):S111-S134. doi:10.2337/dc20-S010

4. Jellinger PS, Handelsman Y, Rosenblit PD, et al. American Association of Clinical Endocrinologists and American College of Endocrinology guidelines for management of dyslipidemia and prevention of cardiovascular disease. Endocr Pract 2017; 23(suppl 2):1-87. doi:10.4158/EP171764.APPGL

5. Mach F, Baigent C, Catapano AL, et al. 2019 ESC/EAS guidelines for the management of dyslipidaemias: lipid modification to reduce cardiovascular risk: The Task Force for the management of dyslipidaemias of the European Society of Cardiology (ESC) and European Atherosclerosis Society (EAS). Eur Heart J 2020; 41(1):111-188. doi:10.1093/eurheartj/ehz455

doi:10.3949/ccjm.87c.06001
In Reply: We thank Dr. Modarressi for bringing up those points, and we are grateful the review was found to be informative. ${ }^{1}$

We agree that, although tendon xanthomas are pathognomonic for familial hypercholesterolemia (FH), xanthelasmas are not. Xanthelasmas are rich cholesterol deposits in the skin of the eyelids that occur in the setting of hypercholesterolemia. ${ }^{2}$ They are nonspecific, but can be seen in patients with $\mathrm{FH}$ because these patients often have extreme hypercholesterolemia. Therefore, we suggest in the article that xanthelasmas could be present in patients with $\mathrm{FH}$ as a physical finding, and we specifically state that xanthomas are the pathognomonic lesions. To the same effect, it is also possible to see a patient with $\mathrm{FH}$ without xanthomas or xanthelasmas.

We also agree with Dr. Modarressi that the lowdensity lipoprotein cholesterol goal of less than $55 \mathrm{mg} /$ dL was based on the 2017 American Association of Clinical Endocrinologists/American College of Endocrinology guideline recommendations (reference 66). ${ }^{3}$

NISHANT P. SHAH, MD, FACC

Duke Heart Center

Durham, NC

HAITHAM M. AHMED, MD

AdvantageCare Physicians

New York, NY

W. H. WILSON TANG, MD

Heart and Vascular Institute

Cleveland Clinic

\section{REFERENCES}

1. Shah NP, Ahmed HM, Tang WH. Familial hypercholesterolemia: detect, treat, and ask about family. Cleve Clin J Med 2020; 87(2):109-120. doi:10.3949/ccjm.87a.19021

2. Nair PA, Singhai R. Xanthelasma palpebrarum - a brief review. Clin Cosmet Investig Dermatol 2017; 11:1-5. doi:10.2147/CCID.S130116

3. Jellinger PS, Handelsman Y, Rosenblit PD, et al. American Association of Clinical Endocrinologists and American College of Endocrinology guidelines for management of dyslipidemia and prevention of cardiovascular disease. Endocr Pract 2017; 23(suppl 2):1-87. doi:10.4158/EP171764.APPGL

doi:10.3949/ccjm.87c.06002 